\title{
FY2010 Annual Report for the Actinide Isomer Detection Project
}

\author{
GA Warren LE Erikson \\ CJ Francy EA Miller \\ JJ Ressler ${ }^{1} \quad$ R Hatarik $^{1}$
}

January 2011

\section{Pacific Northwest} NATIONAL LABORATORY

Proudly Operated by Battelle Since 1965

${ }^{1}$ Lawrence Livermore National Laboratory 


\title{
DISCLAIMER
}

This report was prepared as an account of work sponsored by an agency of the United States Government. Neither the United States Government nor any agency thereof, nor Battelle Memorial Institute, nor any of their employees, makes any warranty, express or implied, or assumes any legal liability or responsibility for the accuracy, completeness, or usefulness of any information, apparatus, product, or process disclosed, or represents that its use would not infringe privately owned rights. Reference herein to any specific commercial product, process, or service by trade name, trademark, manufacturer, or otherwise does not necessarily constitute or imply its endorsement, recommendation, or favoring by the United States Government or any agency thereof, or Battelle Memorial Institute. The views and opinions of authors expressed herein do not necessarily state or reflect those of the United States Government or any agency thereof.

\author{
PACIFIC NORTHWEST NATIONAL LABORATORY \\ operated by \\ BATTELLE \\ for the \\ UNITED STATES DEPARTMENT OF ENERGY \\ under Contract DE-AC05-76RL01830
}

Printed in the United States of America
Available to DOE and DOE contractors from the Office of Scientific and Technical Information,
P.O. Box 62, Oak Ridge, TN 37831-0062;
ph: (865) 576-8401
fax: $(865)$ 576-5728
email: reports@adonis.osti.gov

\begin{abstract}
Available to the public from the National Technical Information Service, U.S. Department of Commerce, 5285 Port Royal Rd., Springfield, VA 22161 ph: (800) 553-6847 fax: $(703) 605-6900$ email: orders@ntis.fedworld.gov online ordering: http://www.ntis.gov/ordering.htm
\end{abstract}

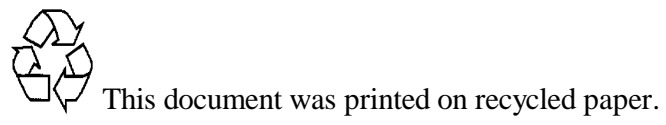




\title{
FY2010 Annual Report for the Actinide Isomer Detection Project
}

\author{
GA Warren LE Erikson \\ CJ Francy EA Miller \\ JJ Ressler $^{1} \quad$ R Hatarik $^{1}$
}

January 2011

Prepared for the U. S. DEPARTMENT OF ENERGY under Contract DE-AC05-76RL01830

Pacific Northwest National Laboratory

Richland, WA 99354

${ }^{1}$ Lawrence Livermore National Laboratory 


\section{Executive Summary}

This project seeks to identify a new signature for actinide element detection in active interrogation. This technique works by exciting and identifying long-lived nuclear excited states (isomers) in the actinide isotopes and/or primary fission products. Observation of isomers in the fission products will provide a signature for fissile material. For the actinide isomers, the decay time and energy of the isomeric state is unique to a particular isotope, providing an unambiguous signature for SNM.

This project entails isomer identification and characterization and neutron population studies. This document summarizes activities from its third year - completion of the isomer identification characterization experiments and initialization of the neutron population experiments.

The population and decay of the isomeric state in ${ }^{235} \mathrm{U}$ remain elusive, although a number of candidate gamma rays have been identified. In the course of the experiments, a number of fission fragment isomers were populated and measured [Ressler 2010]. The decays from these isomers may also provide a suitable signature for the presence of fissile material.

The project started FY2010 reviewing the beam test data acquired at TUNL in September 2009. Based on results from those measurements, the project management decided to conduct the measurements at the $88^{\prime \prime}$ cyclotron at LBNL, which provided similar neutron flux but better beam time structure for these measurements. PNNL, LLNL and LBNL conducted test measurements in March 2010 to study issues such as beam intensity, beam profile, and background rates for the measurements. Neutron production measurements were conducted in July 2010 at LBNL. The data from those measurements are still under analysis. A malfunctioning Time-to-Digital Converter in the data acquisition system may limit the utility of the data. There was a second timing information system using Time-to-Amplitude Converters. Analysis is ongoing as to whether this information may enable the successful analysis of the experimental data.

Future work will include a follow-up measurement scheduled for December 2010 at LBNL. New measurements will incorporate lessons learned from the July 2010 measurements. Analysis of both the July and December experiments will be complete in a few months. The project will draft a research paper for submission to a peer-reviewed journal if the conclusions from the measurements warrant publication. 


\section{Acronyms and Initialisms}

$\begin{array}{ll}\text { ADC } & \text { Analog-to-Digital Converter } \\ \text { FWHM } & \text { Full-width-at-half-maximum } \\ \text { HEU } & \text { Highly Enriched Uranium } \\ \text { HPGe } & \text { High-Purity Germanium } \\ \text { LBNL } & \text { Lawrence Berkeley National Laboratory } \\ \text { LLNL } & \text { Lawrence Livermore National Laboratory } \\ \text { PNNL } & \text { Pacific Northwest National Laboratory } \\ \text { SNM } & \text { Special Nuclear Materials } \\ \text { TAC } & \text { Time-to-Amplitude Converter } \\ \text { TDC } & \text { Time to Digital Converter } \\ \text { TUNL } & \text { Triangle Universities Nuclear Laboratory } \\ \text { DU } & \text { Depleted uranium }\end{array}$




\section{Contents}

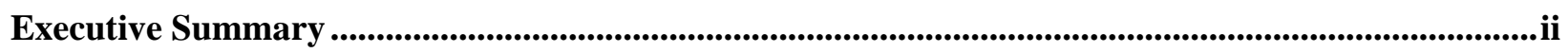

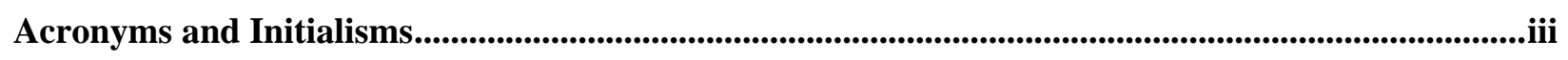

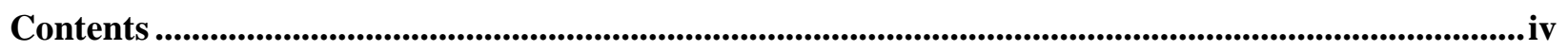

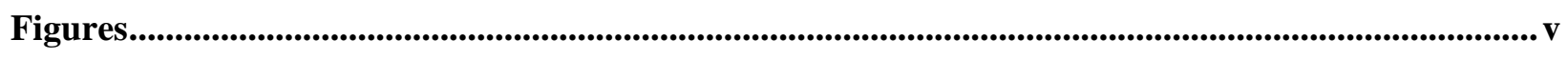

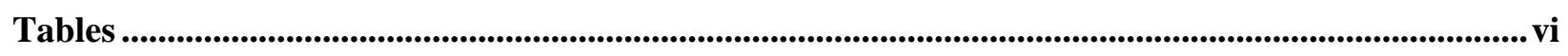

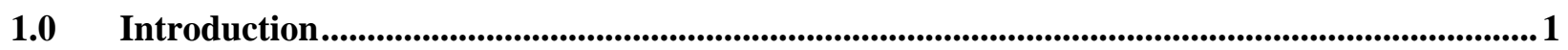

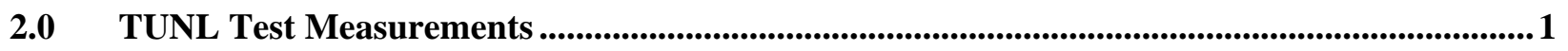

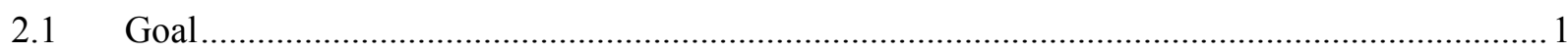

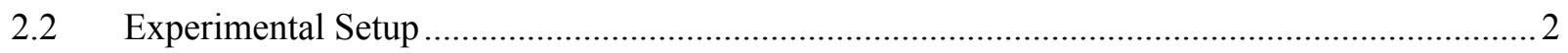

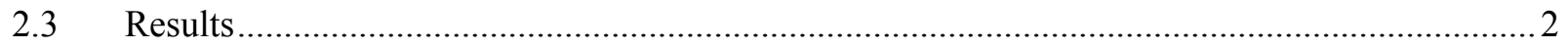

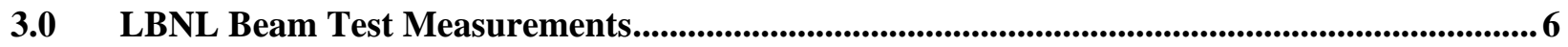

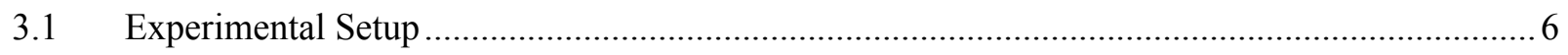

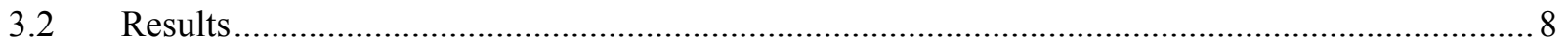

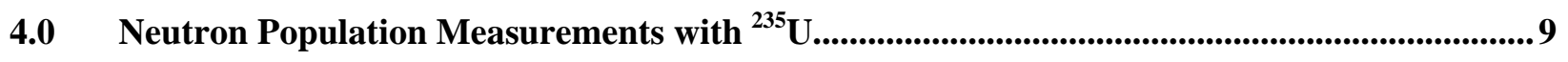

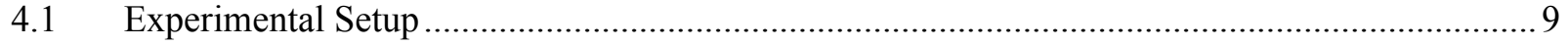

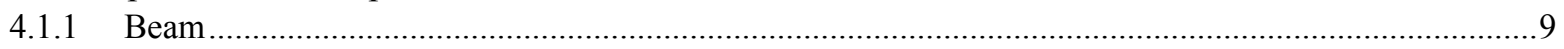

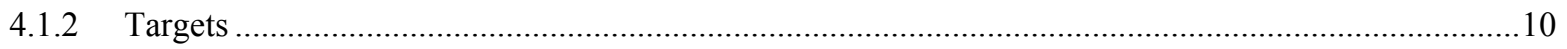

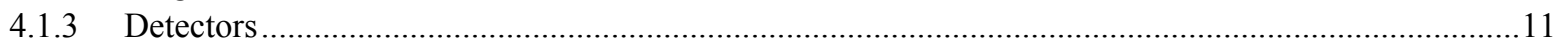

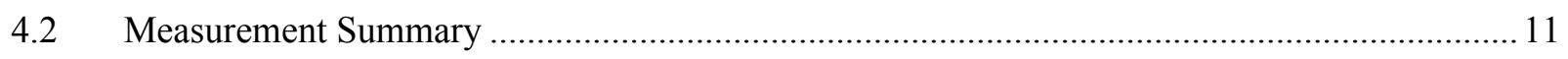

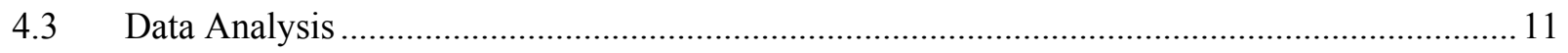

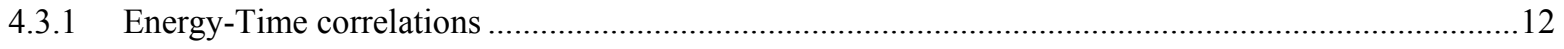

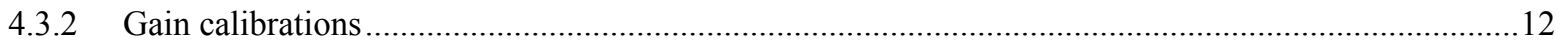

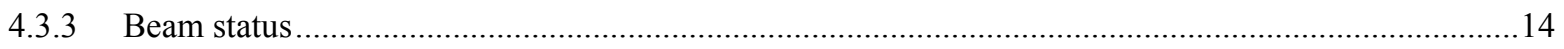

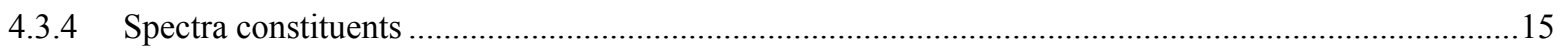

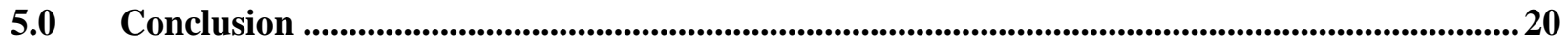

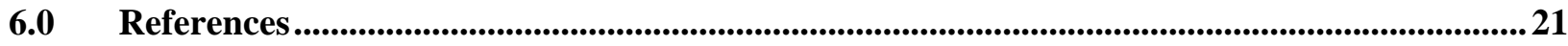

7.0 References........................................................................................ Error! Bookmark not defined. 


\section{Figures}

Figure 1: An example of unshielded gamma detector positions at $135^{\circ}$ relative to the beam axis. The target is in the center. The deuterium-filled gas target is located within the wall of shielding behind the detectors. The shielding wall consisted of concrete, lead, and doped polyethylene.

Figure 2: Neutron timing in the TUNL setup. The peak at $\mathrm{T}=0 \mathrm{~ns}$ is the prompt flash from the primary neutron beam. Break-up neutrons are observed near $\mathrm{T}=50 \mathrm{~ns}$ relative to the prompt flash (purple arrow). At $\mathrm{T}=200 \mathrm{~ns}$ (green arrow), neutrons are also observed due to incomplete blocking of the deuteron beam......

Figure 3: Experimentally-measured decay of the ${ }^{238} \mathrm{U}$ shape isomer [Kantele 1984].....................3

Figure 4: Gamma-ray spectrum for each HPGe detector.........................................................

Figure 5: Timing structure of the TUNL dataset. A) illustrates the timing for all $\gamma \mathrm{s}, \mathrm{b}$ ) illustrates the timing for prompt events (and as a result corresponds to the beam timing), and c) corresponds to the timing for a known background line.

Figure 6: Cross section for the population of the $2557-\mathrm{keV}$ shape isomer in ${ }^{238} \mathrm{U}$ via the ${ }^{238} \mathrm{U}\left(\mathrm{n}, \mathrm{n}^{\prime}\right)$ reaction, as compared to similar $\left(\mathrm{n}, \mathrm{n}^{\prime}\right)$ data from Chatterjee et al [1981] at 14.5 $\mathrm{MeV}$ and Wolf et al. [1974]. The lines indicate theoretical predictions for this cross section (see reference text), which are clearly inconsistent with our data (in blue). The figure, with the exception of our data, was taken from [Chatterjee 1981].

Figure 7: Diagram of the cyclotron and experimental facility for the LBNL measurements. The measurement rooms, Cave 0/1 and Cave 0/2, are in the upper left corner of the diagram.........7

Figure 8: Neutron and photon discrimination with the liquid scintillator. 8

Figure 9: HPGe spectra from Runs101, 91 and 93 showing the broad background induced in the HPGe detector in a field of thermal neutrons

Figure 10: HEU target from PNNL

Figure 11: HPGe setup for the July run. Two clover detectors were placed approximately $11.5 \mathrm{~cm}$ from the secondary target.

Figure 12: HPGe energy for leaf 4 of clover 1 relative to the TAC value. The energy significantly shifts when the neutron beam turns off or on.

Figure 13: Energy shifts for neutron flux changes in leaf 4 of clover 1. All energies exhibit the same gain shift (a), and the magnitude of the shift is equal, though opposite in sign, when the neutron beam turns on/off (b). Note that the "off-to-on" data is opposite in sign and the TAC value is shifted by $50 \mu$ s to overlay the "on-to-off" shift. 
Figure 14: HPGe-beam TAC value in coincidence with the scintillators as a function of event number. The event number is roughly proportional to time. All three scintillators used counted in the same manner; i.e., this observation is not due to scintillator noise.

Figure 15: HPGe-TAC value in coincidence with the scintillators as a function of event number for run 161

Figure 16: Sample of background subtraction using the gamma spectrum collected during the beam on period for runs $149-158$

Figure 17. Gamma spectra gated by beam on and off conditions for runs $149-158 \ldots \ldots \ldots \ldots \ldots \ldots . . . .16$

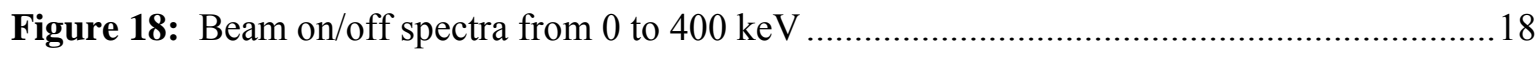

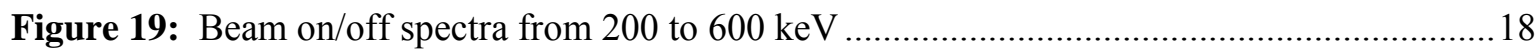

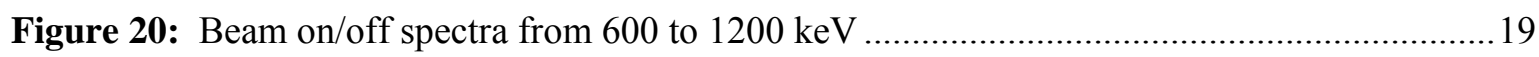

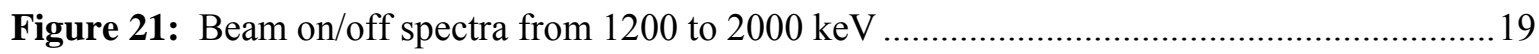

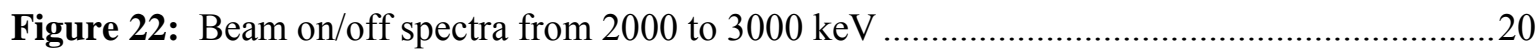

\section{Tables}

Table 1: Isotopic Mass of HEU Sample 


\subsection{Introduction}

This project seeks to identify a new signature for actinide element detection in active interrogation. This technique works by exciting and identifying long-lived nuclear $(\sim 10-100 \mathrm{~ms})$ excited states (isomers) in the actinide isotopes and/or primary fission products. Observation of isomers in the fission products will provide a signature for fissile material. For the actinide isomers, the decay time and energy of the isomeric state is unique to a particular isotope, providing an unambiguous signature for special nuclear materials (SNM).

The high-energy gamma rays emitted from the actinide isomer decay allow the photon emission to be easily identifiable for two reasons. First, the gamma-ray background is low at the expected isomeric decay energy (2-3 MeV). Second, this energy is the least attenuated through any material. Moreover, the emission of isomeric decay photons will fall within an optimal time window between the end of the neutron pulse and the onset of gamma rays arising from neutron-induced beta decay products. The unique characteristics of the high energy and fast decay time for the actinide isomers provide an unambiguous signature for the emitting isotope. The scientific background for this new signature is described in Annual Progress Report for Actinide Isomer Detection (2009) [Ressler 2009].

This three-year project was proposed to search for the actinide isomers, with a focus on ${ }^{235} \mathrm{U}$. In the first year, experiments were conducted to characterize actinide isomers of interest, as discussed in Annual Progress Report for Actinide Isomer Detection (2008)[Ressler 2008]. Several candidate signatures of

${ }^{235} \mathrm{U}$ isomers were identified, although the results were not conclusive. The second year, analysis was completed on the characterization measurements and neutron population experiments were initiated. One of the results of the analysis was the discovery of several new isomers of fission products [Ressler 2009]. The initial neutron population test measurements were completed at Triangle Universities Nuclear Laboratory (TUNL) near the end of FY2009. One of the findings of those tests was that the neutron beam was not as clean in time or energy as desired for the measurements. As a result, the plan for the third year was to complete the neutron population measurements at Lawrence Berkeley National Laboratory (LBNL) at the 88" cyclotron. In FY2010, a pair of test measurements was completed to assess the experimental environment (room background, beam structure, beam intensity) at LBNL. In late July 2010, the first stage of the neutron production measurement was completed. Further measurements are planned for FY2011.

This report covers the progress of the project completed in FY2010. It will discuss the TUNL measurements, followed by the test measurements at LBNL, and then the production measurements at LBNL. Results from each of these experiments will be discussed, as well as future efforts.

\subsection{TUNL Test Measurements}

\subsection{Goal}

The population of the isomers in a neutron beam must also be investigated to determine if actinide isomer detection is feasible in an interrogation system. The initial neutron experiment was run September 15 through September 18, 2009 at TUNL. This facility has the ability to provide neutron beams with well- 
defined energies in the range of $5-15 \mathrm{MeV}$. The purpose of this first experiment was to gain experience and optimize the experimental setup for the main experimental campaign.

\subsection{Experimental Setup}

TUNL generated neutrons using their 10-MV FN tandem accelerator by directing a deuteron ion beam on a deuteron gas target. The reaction that generates the neutrons is $\mathrm{d}+\mathrm{d} \rightarrow\left[{ }^{4} \mathrm{He}\right]^{*} \rightarrow{ }^{3} \mathrm{He}+\mathrm{n}$, which, in principle, produces monoenergetic neutrons up to the energy loss through the target gas. The beam was pulsed in time to provide the necessary time structure for the isomer measurements. Photons were detected with by two large high-purity germanium (HPGe) detectors. Figure 1 is a photo of the detectors during the experiment. The detectors had an efficiency of $120 \%$ and $130 \%$ relative to a 3 " diameter , 3 " long $\mathrm{NaI}$ crystal at $1.3 \mathrm{MeV}$. A 1.5" diameter scintillator was placed along the beam axis to monitor the beam flux and energy resolution. The DU target was $5 \mathrm{~cm} \times 12 \mathrm{~cm} \times 0.3 \mathrm{~cm}$.

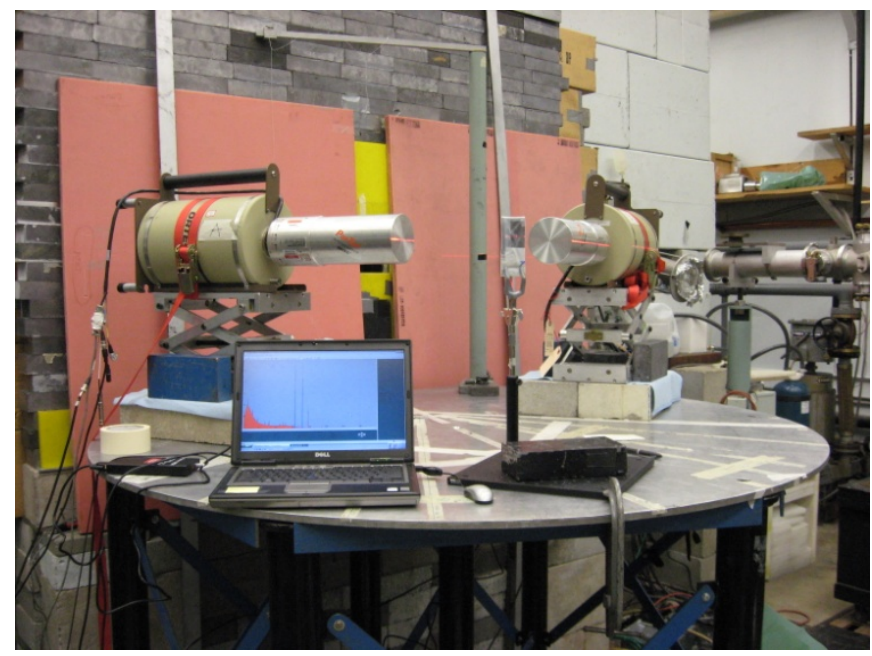

Figure 1: An example of unshielded gamma detector positions at $135^{\circ}$ relative to the beam axis. The target is in the center. The deuterium-filled gas target is located within the wall of shielding behind the detectors. The shielding wall consisted of concrete, lead, and doped polyethylene.

\subsection{Results}

This work was also hampered by significant deuteron break-up reactions in the gas target. Following the primary neutron peak, lower-energy neutrons at delayed times relative to the prompt peak were observed. For isomeric studies, this delayed neutron pulse prevents clean isolation of prompt and delayed photon transitions. A further complication included the observation that the beam is not fully blocked, allowing a small flux of neutrons to be created every 200 ns. The timing effects are highlighted in Figure 2. 


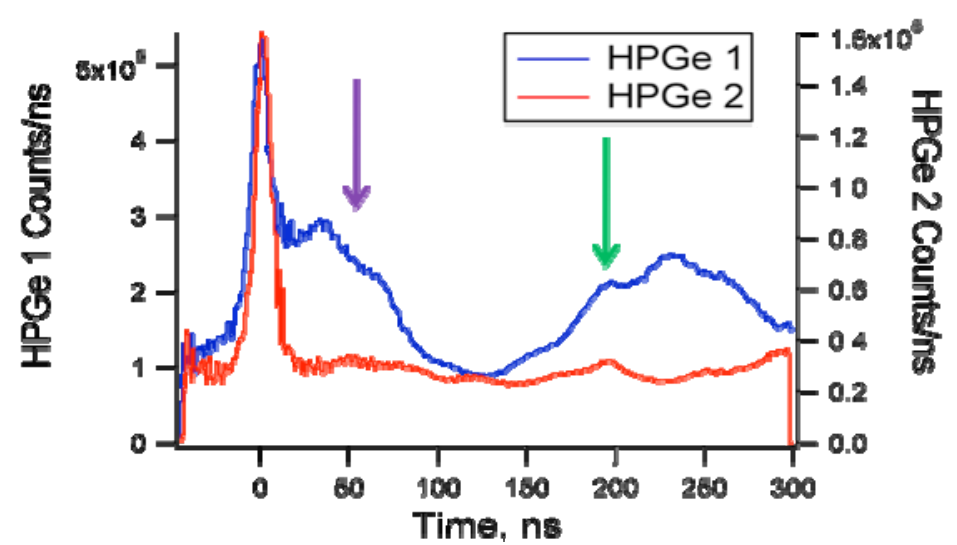

Figure 2: Neutron timing in the TUNL setup. The peak at $\mathrm{T}=0 \mathrm{~ns}$ is the prompt flash from the primary neutron beam. Break-up neutrons are observed near $\mathrm{T}=50 \mathrm{~ns}$ relative to the prompt flash (purple arrow). At $\mathrm{T}=200 \mathrm{~ns}$ (green arrow), neutrons are also observed due to incomplete blocking of the deuteron beam.

The neutron beam flux was determined using known inelastic scattering processes. Measurements of gamma rays generated from neutron inelastic scattering on iron were conducted. The inelastic cross section for $8 \mathrm{MeV}$ neutrons on ${ }^{56} \mathrm{Fe}$ is 1.36 barns according to ENDF/B-VII [Chadwick 2006]. Since most of the ${ }^{56} \mathrm{Fe}$ states decay through the $846-\mathrm{keV}$ level, one can reasonably assume that cross section for the generation of $846-\mathrm{keV}$ gamma rays from inelastic scattering. From this information, we extracted the neutron flux as ranging from 2 to $20 \times 10^{4} \mathrm{n} /\left(\mathrm{s} \mathrm{cm}^{2} \mu \mathrm{A}\right)$. These estimates are consistent with previous neutron flux measurements at the TUNL facility.

As a check on the feasibility of conducting the search for ${ }^{235} \mathrm{U}$ isomers at TUNL, a measurement searching for the known isomer of ${ }^{238} \mathrm{U}$ was conducted. The decay of the ${ }^{238} \mathrm{U}$ shape isomer has been observed via ${ }^{238} U\left(n, n^{\prime}\right)$ inelastic scattering [Chatterjee 1981] and ${ }^{238} U(d, p n)$ reactions [Kantele 1984]. Kantele suggests that the shape isomer, which has an energy of $2557.6 \mathrm{MeV}$, decays following the scheme depicted in Figure 3.

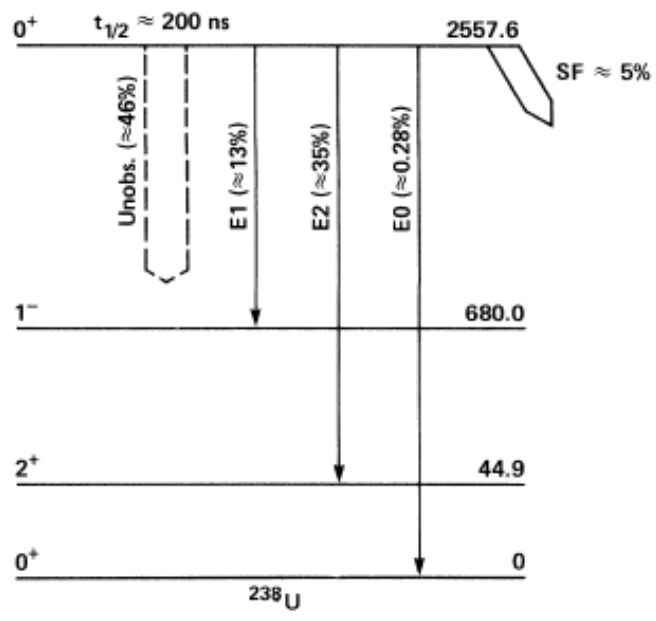

Figure 3: Experimentally-measured decay of the ${ }^{238} \mathrm{U}$ shape isomer [Kantele 1984] 
The most prominent line should be the 2514-keV decay (35\%), followed by the $1878-\mathrm{keV}$ decay (13\%). As seen in Figure 4, any possible 1878-keV decay is obscured by a background peak; however a small peak is clearly visible at $2514 \mathrm{keV}$. Unfortunately, there is no $\gamma-\gamma$ coincidence data to support a claim that the $2514-\mathrm{keV}$ line is from the shape isomer decay, as the coincident decay ( $44 \mathrm{keV}$ ) is below our detection threshold. The 680 and $1878 \mathrm{keV}$ coincidences are, in principle, observable; however, because the $1878-\mathrm{keV}$ line has a small probability $(13 \%)$, this experiment did not have the necessary statistics to observe this coincidence.

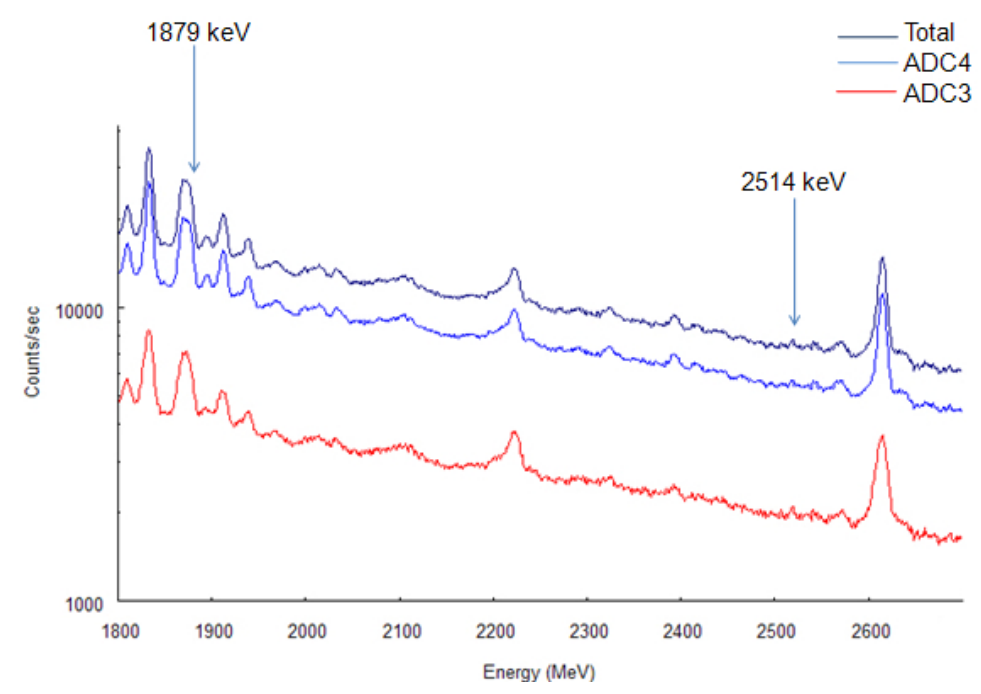

Figure 4: Gamma-ray spectrum for each HPGe detector

Because the origin of the 2514-keV $\gamma$-ray cannot be attributed to the decay of a ${ }^{238} \mathrm{U}$ shape isomer using $\gamma$ $\gamma$ coincidence, all other possible origins must be eliminated. This requires a careful analysis of all possible background contributions. Ambient room background, beam + room background, natural target decay background, and beam + lead and iron background spectra were all analyzed and compared to the beam on target data presented in Figure 4. Pre- and post-target irradiation measurements of the decays from the target were also analyzed to search for an increase in grown-in reaction products. The results of this analysis indicate that the $2514-\mathrm{keV}$ line is indeed the result of neutron beam on depleted uranium (DU) target interactions, as it is not present in any of the passive or beam-on background data.

The next step was to understand the timing properties of the beam and the subsequent $\gamma$-decays. Figure 5 plots the time for $\gamma$-ray events, with a) showing all $\gamma \mathrm{s}, \mathrm{b}$ ) showing times for a known prompt $\gamma$-decay resulting from ${ }^{238} \mathrm{U}\left(\mathrm{n}, \mathrm{n}^{\prime}\right)$, and c) showing times for a known background line. From this, the basic timing structure can be determined. Figure $5 \mathrm{~b}$ illustrates the true structure of the beam, since it is gated on the decay of a prompt $\gamma$-ray resulting from beam on target interactions. The primary beam bunch is incident on the target, followed $200 \mathrm{~ns}$ later by a smaller beam bunch that results from the beam leaking through the chopper. Therefore, the $400 \mathrm{~ns}$ between beam bunches is contaminated by a smaller beam bunch at $200 \mathrm{~ns}$. This is a serious problem, as it means instead of having $400 \mathrm{~ns}$ after the primary beam bunch to look for delayed products there is only $200 \mathrm{~ns}$, since the second "contaminant" bunch can result in new beam-on-target interactions. The half-life of the shape isomer decay is approximately $200 \mathrm{~ns}$ [Kantele 
1984], meaning the imperfect beam chopping severely limits our ability to isolate its decay from other events.
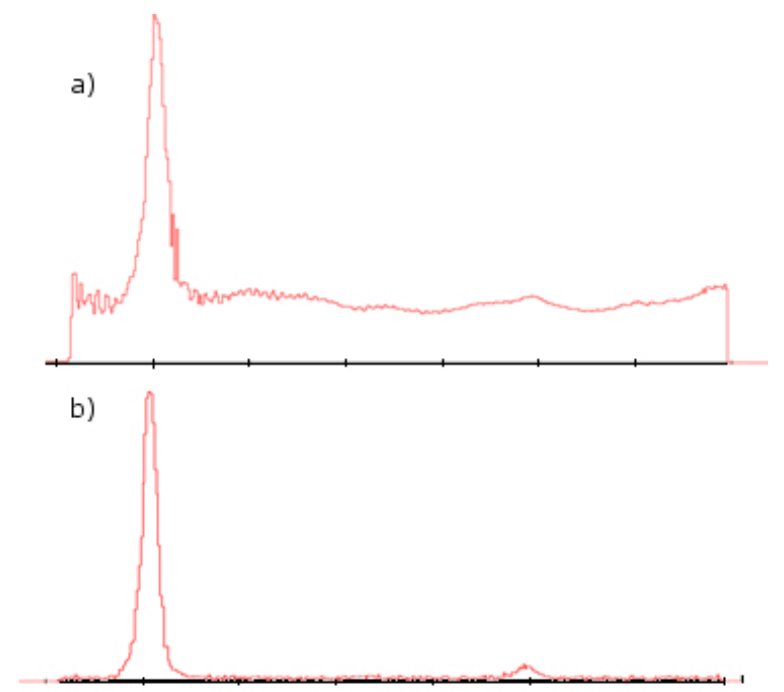

c)

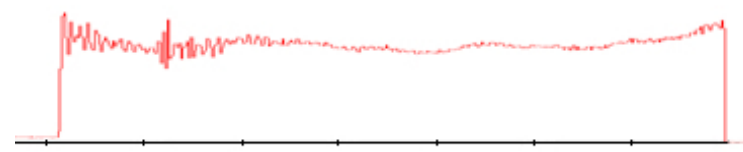

Figure 5: Timing structure of the TUNL dataset. A) illustrates the timing for all $\gamma \mathrm{s}, \mathrm{b}$ ) illustrates the timing for prompt events (and as a result corresponds to the beam timing), and c) corresponds to the timing for a known background line.

Careful background studies indicated that the $2514-\mathrm{keV} \gamma$-ray is the result of a ${ }^{238} \mathrm{U}+\mathrm{n}$ reaction. Low statistics coupled with the leaking beam bunch means that timing information cannot be used to verify its status as a 200-ns isomer decay. Additionally, there is no measurable coincident $\gamma$-decay to place it in a level scheme. Careful examination of existing nuclear decay data reveals that there is no known $\gamma$-decay in ${ }^{238} \mathrm{U}$ with similar energy, so there is a very distinct possibility that the observed $2514-\mathrm{keV}$ peak is the result of the decay of the ${ }^{238} \mathrm{U}$ shape isomer. Assuming for a moment that this is the case, the cross section can be determined and compared to the existing ${ }^{238} U\left(n, n^{\prime}\right){ }^{238} U(E \gamma=2557 \mathrm{keV})$ data published by Chatterjee et al [1981]. The result is shown in Figure 6. The large error bars are the result of the large energy spread of the neutron beam and the limited statistics of the 2514-keV peak. Unfortunately, there are too many assumptions in this analysis for this result to be publishable. 


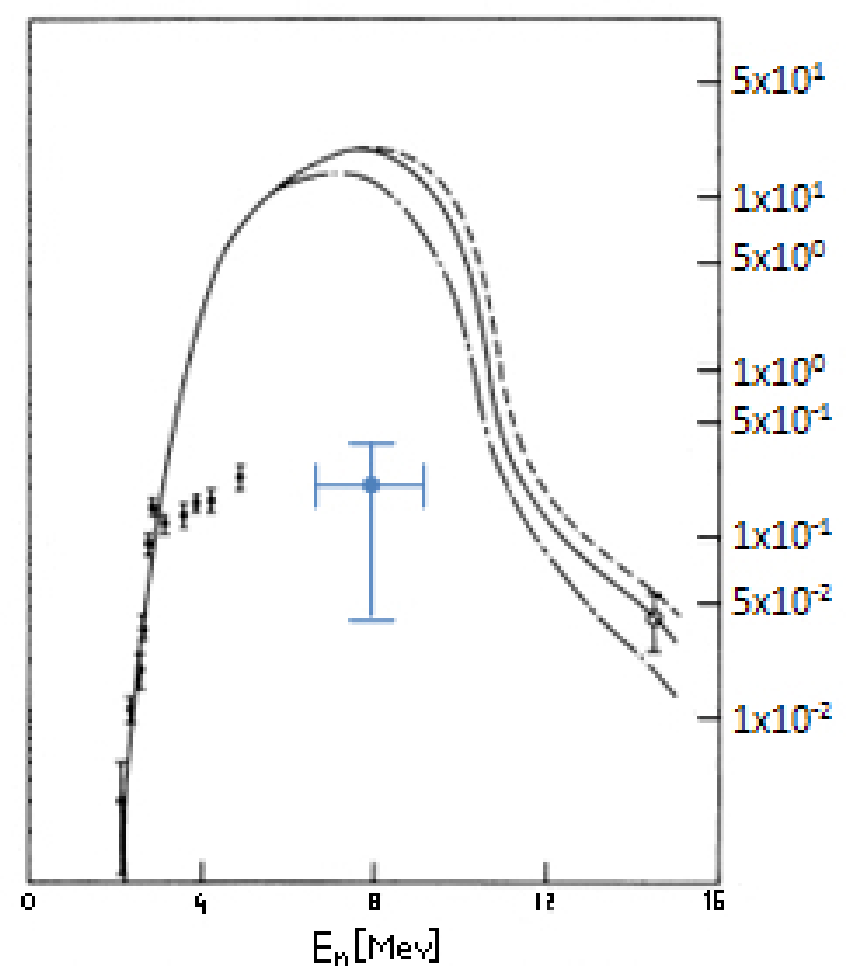

Figure 6: Cross section for the population of the $2557-\mathrm{keV}$ shape isomer in ${ }^{238} \mathrm{U}$ via the ${ }^{238} \mathrm{U}\left(\mathrm{n}, \mathrm{n}^{\prime}\right)$ reaction, as compared to similar (n,n') data from Chatterjee et al [1981] at $14.5 \mathrm{MeV}$ and Wolf et al. [1974]. The lines indicate theoretical predictions for this cross section (see reference text), which are clearly inconsistent with our data (in blue). The figure, with the exception of our data, was taken from [Chatterjee 1981].

\subsection{LBNL Beam Test Measurements}

Prior to performing an isomer experiment, the researchers examined neutron production capability at LBNL. While experiments utilizing neutrons have been used by other experimentalists, isolated secondary targets and HPGe gamma detectors had not been used. The project used sixteen hours of beam development time on May 16, 2010 to gain an understanding of the neutron fields in the experimental area and their effects on an HPGe.

\subsection{Experimental Setup}

A $25-\mathrm{MeV}$ deuteron beam struck a thick tantalum disk with a copper backing in the cyclotron vault (see Figure 7). Neutrons from the break-up reaction were emitted into experimental Cave 0 . This cave has two sections separated by a shielding wall. Cave $0 / 1$ is a small space where the neutron beam is wellfocused, while Cave $0 / 2$ is a larger area. For the test runs, secondary targets of iron and lead were used. A liquid scintillator (BC 501-A from Saint Gobain) and small plastic scintillator were used for neutron detection. The liquid scintillator was $\sim 11 \mathrm{~cm}^{2}$ and the plastic scintillator was smaller. The liquid scintillator employed pulse-shape discrimination to delineate between photon and neutron events (Figure 8). Photons were detected with a 25\% n-type HPGe detector. This detector was non-optimal, and appeared to undergo voltage sparks with only $\sim 30 \%$ of the depletion bias applied. The detector was run with low voltage, reducing the detection efficiency and resolution dramatically. However, this detector 
was sufficient for the beam tests. A Time-to-Digital Converter (TDC), and Analog-to-Digital Converter (ADC) were used for data collection.

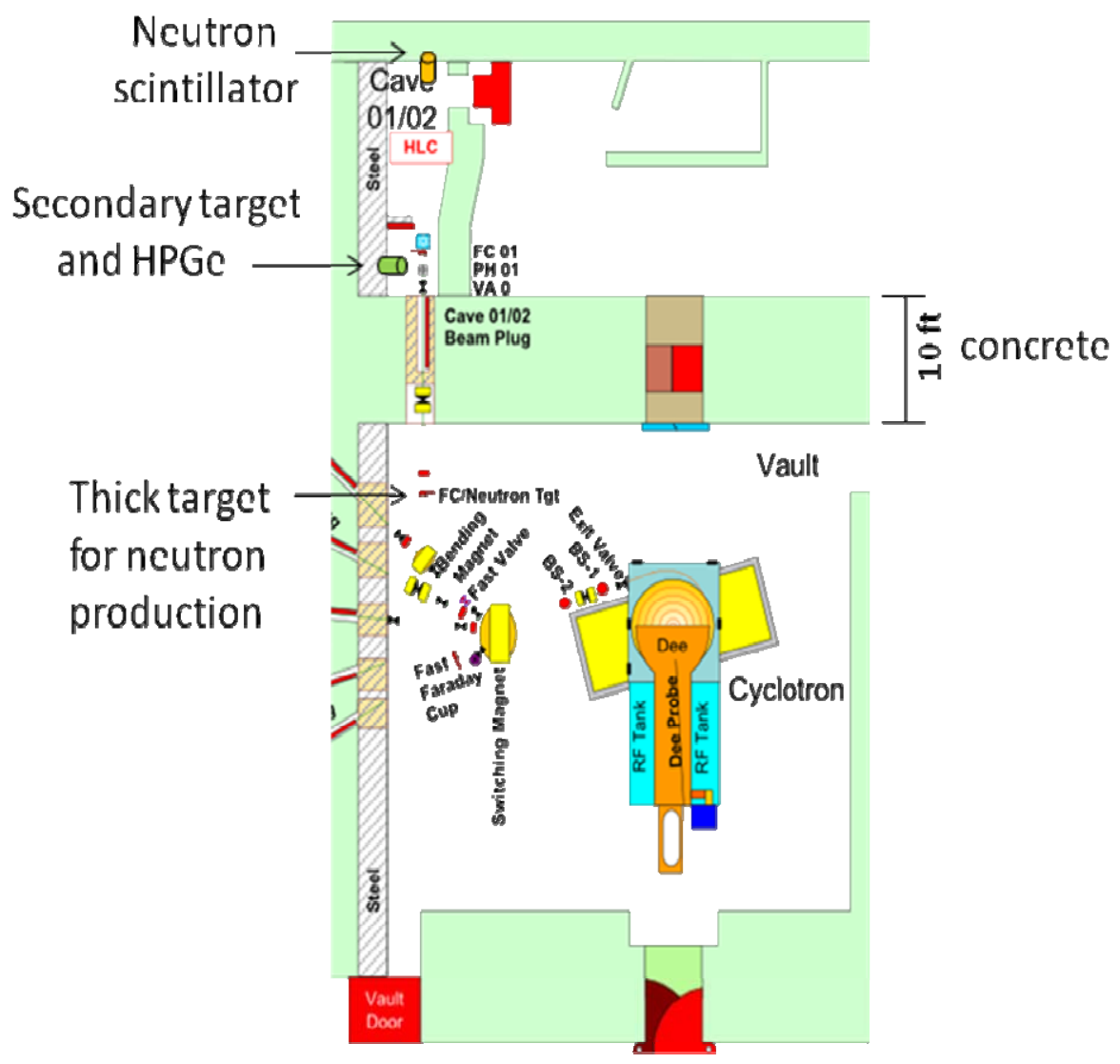

Figure 7: Diagram of the cyclotron and experimental facility for the LBNL measurements. The measurement rooms, Cave 0/1 and Cave 0/2, are in the upper left corner of the diagram. 


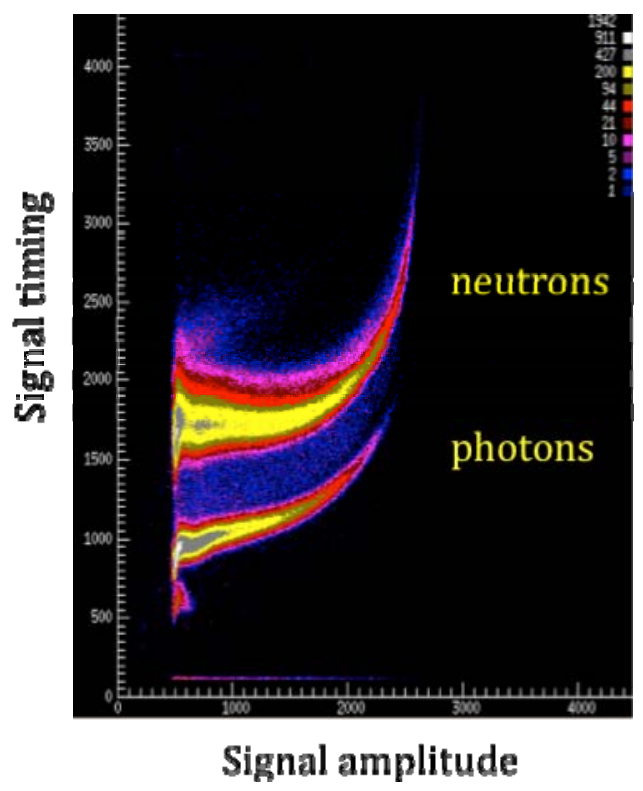

Figure 8: Neutron and photon discrimination with the liquid scintillator

\subsection{Results}

Over the 16-hour development period, approximately 50 data runs were collected. The neutron beam area was mapped out with the scintillator detectors, and the neutron effects on the HPGe were examined.

- From the scintillator mapping, the neutron beam was determined to be well-collimated in Cave 0/1 with a full-width-at-half-maximum (FWHM) of approximately $10 \mathrm{~cm}$. The beam broadens as it progresses into Cave $0 / 2$, but not dramatically.

- Assuming a $10 \%$ detector efficiency, the break-up reaction produced approximately $2.5 \times 10^{4} \mathrm{n} / \mathrm{s}-$ $\mathrm{cm}^{2}-\mu \mathrm{A}$ in Cave 0/1. This value was reduced to $\sim 1.5 \times 10^{4}$ neutrons $/\left(\mathrm{s} \mathrm{cm}^{2} \mu \mathrm{A}\right)$ in Cave $0 / 2$. This flux is comparable to what was achieved at TUNL, which was $\sim 2 \times 10^{4} \mathrm{n} /\left(\mathrm{s} \mathrm{cm}^{2} \mu \mathrm{A}\right)$.

- The HPGe detector was tested in Cave 0/1 and Cave 0/2. While neutron fluxes are lower in the latter cave, the background thermal neutron rate was significantly lower. Thermal neutron interactions in the germanium crystal cause a large background due in large part to neutron capture reactions on the germanium nuclei. This effect is greatly reduced when the detector is placed in the outer cave (see Figure 9).

- During this development run, preliminary tests of the beam pulsing were also undertaken. The pulsing system is the same as was utilized for the particle-induced experiments, and operated as expected. 


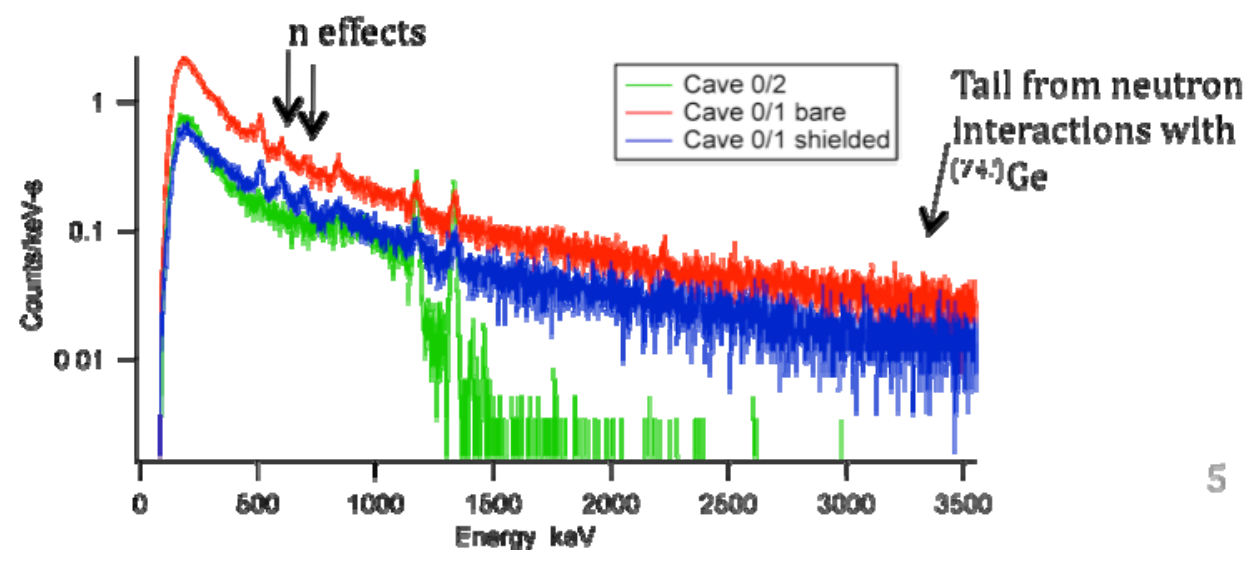

Figure 9: HPGe spectra from Runs101, 91 and 93 showing the broad background induced in the HPGe detector in a field of thermal neutrons

\subsection{Neutron Population Measurements with ${ }^{235} \mathrm{U}$}

The second beam time at LBNL focused on observing isomeric decays following neutron interrogation of a small ${ }^{235} \mathrm{U}$ sample. The isomer experiment ran from July 23-26, and July 28-30.

Eight hours were allocated on July 23, 2010, just prior to the experimental run for beam development. This time was used to measure the neutron flux and beam size in Cave 0/2 to ensure proper placement of the HPGe detectors.

\subsection{Experimental Setup}

\subsubsection{Beam}

The beam was produced in an analogous fashion as for the beam development run, except that a small beryllium disk was mounted on the thick copper break-up target backing. Neutron production with beryllium is anticipated to be significantly greater than with tantalum, copper, or other higher- $Z$ elements [Meulders 1975]. The disk was $1.5 \mathrm{~mm}$ thick, and placed in thermal contact with the thick $(1.5 \mathrm{~cm})$ copper plate. The copper backing provided further break-up capability, captured produced protons, and stopped deuterium ions that did not undergo break-up. From the 8-hour development run, the neutron rate with the beryllium target provided only a modest increase in the neutron rate.

For the first phase of the experiment, three different beam energies were examined. Deuterons at $25 \mathrm{MeV}, 20 \mathrm{MeV}$ and $15 \mathrm{MeV}$ were used to produce neutrons of approximately 11.4, 8.9 and $6.4 \mathrm{MeV}$, respectively. The second phase of the experiment used a $25-\mathrm{MeV}$ beam energy. This energy covers the peak of the ${ }^{235} U(n, 2 n){ }^{234} U$ cross section, as well as ${ }^{235} U(n, f)$. The broad energy of the neutron energy distribution will also likely cover the expected peak for the ${ }^{235} \mathrm{U}$ isomeric $\left(\mathrm{n}, \mathrm{n}^{\prime}\right)$. The inelastic isomer population is expected to peak near $8 \mathrm{MeV}$ neutron energy.

The beam was pulsed at $100 \mu \mathrm{s}$ or $50 \mu \mathrm{s}$, with a $50 \%$ duty cycle. Most of the beam time was taken with the $50-\mu$ s pulse structure, for a maximum sensitivity to isomeric decays with 10 to 20 - $\mu$ s half-lives. 


\subsubsection{Targets}

Targets of iron, lead and highly-enriched ${ }^{235} \mathrm{U}$ (HEU) were mounted on a cardboard frame in front of the HPGe detectors. The HEU target was prepared by PNNL and consisted of 0.4905 gm of $99.89 \%$ enriched uranium. It consisted of one-and-a-half circles of uranium metal. Each circle was $\sim 5$ mils thick, about $1 / 2$ " in diameter, and weighed $0.327 \mathrm{gm}$. The isotopics of the HEU are as shown in Table 1.

Table 1: Isotopic Mass of HEU Sample

\begin{tabular}{|l|l|}
\hline Isotope & $\%$ Mass \\
\hline${ }^{235} \mathrm{U}$ & $99.89 \%$ \\
\hline${ }^{234} \mathrm{U}$ & $0.035 \%$ \\
\hline${ }^{236} \mathrm{U}$ & $0.025 \%$ \\
\hline${ }^{238} \mathrm{U}$ & $0.053 \%$ \\
\hline
\end{tabular}

The target holder consisted of three pieces (Figure 10). A structure frame in the shape of football "goal posts," foil that wrapped around the HEU, and wire that suspended the foil between the goal posts of the frame. Iron was selected as the material for the target holder. Iron does not activate easily, and it provides a strong "beam-on" signal through inelastic neutron.

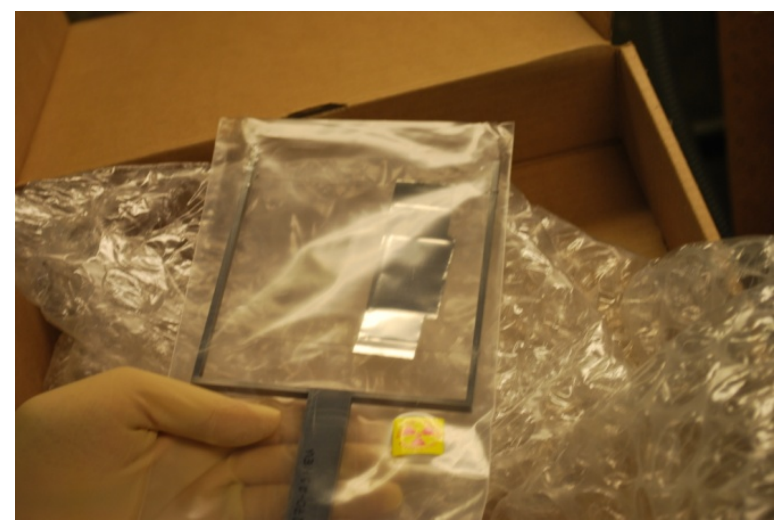

Figure 10: HEU target from PNNL

The HEU was packaged in two sets of metal foils of $99 \%$ iron that were $0.025 \mathrm{~mm}$ thick. The inner set of foils was made of two 2 " squares of the foil welded to form four quadrants - each opening out on two adjacent sides and welded closed on the other two sides. The circle and half-circle of the HEU were inserted into two adjacent quadrants of the inner set of foils. The inner foils were then placed inside a set of outer foils. The outer foils were shaped by starting with a 2-inch "ribbon" of foil, folding over on itself from both ends with the middle portion extending outward on one side wider than the rest of the loop of foil. The bottom and top portion of the outer foils were welded horizontally and along one of the vertical sides, leaving an opening for inserting the HEU-filled inner foils. The two ends of the ribbon of the outer 
foils were welded in such a way as to leave room for the iron wire to be threaded through them to be attached to the posts of the structural frame.

The iron wire is $99.99 \%$ pure iron and is $0.020^{\prime \prime}$ in diameter. The goal-post frame was machined out of solid pieces of A36 ASTM A1018 SS GR 36 Type 2 Structural Steel, 10" x 10" x 1/4". The HEU target was not removed from the plastic bag during the measurement.

\subsubsection{Detectors}

Photons were detected in two large-volume HPGe clover detectors. Clover detectors are comprised of four close-packed crystals of $\sim 25 \%$ efficiency each. The two detectors were placed close to the target at $\sim 90^{\circ}$ and $60^{\circ}$.

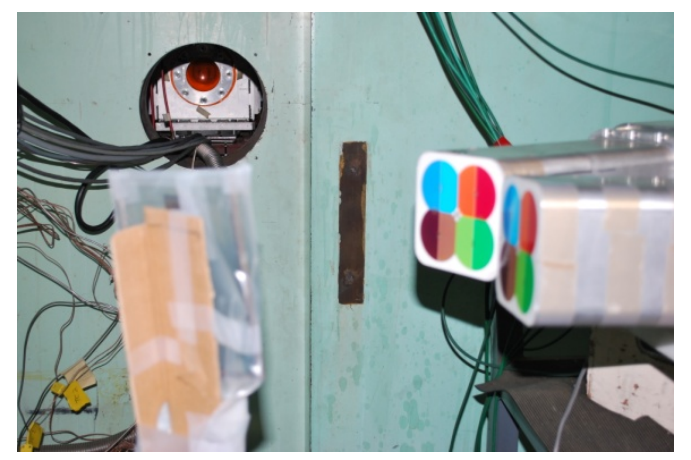

Figure 11: HPGe setup for the July run. Two clover detectors were placed approximately $11.5 \mathrm{~cm}$ from the secondary target.

The $5-\mathrm{cm}^{2}$ liquid scintillator used in the beam development run was again employed. It was placed at $0^{\circ}$ relative to the neutron beam axis and was used to monitor the beam pulsing and neutron flux.

Data was recorded using a VME-based data acquisition system. Signals from the detectors were split and routed to record time and energy information using a TDC and ADC, respectively. Also, the number of pulses was counted with a scaler. In addition to the TDC, the first gamma detector signal was used to generate the stop for a Time-to-Amplitude Converter (TAC).

\subsection{Measurement Summary}

A variety of measurements were conducted during the July beam time. The experiments began with an 8 -hour beam development period in which the neutron rate in Cave $0 / 2$ was examined. Test measurements were then conducted on iron and lead, as they both easily populated isomer states that serve as a means to test the experimental system. The beam time structure for these test measurements was $100 \mu$ s on followed by $100 \mu$ s off. Measurements were then conducted using the HEU target for deuteron beam energies of 25, 20 and $15 \mathrm{MeV}$. Most of the measurements were conducted with a beam time structure of $50 \mu \mathrm{s}$ on, $50 \mu \mathrm{s}$ off; however, the initial measurements at $25 \mathrm{MeV}$ included roughly 12 hours with beam structure of $100 \mu$ s on, $100 \mu$ s off.

\subsection{Data Analysis}

A number of unanticipated difficulties occurred in the data analysis of the neutron production runs. 


\subsubsection{Energy-Time correlations}

Both the test and production runs utilized the VME data acquisition system purchased under the project. This system consists of a TDC for timing information, an ADC for energy and TAC information, and a scaler. When the data acquisition is triggered, these modules are read out and saved to disk.

For the test runs, the scaler was not used. The ADC and TDC data was correlated, and the events were easily separated. The test runs had low data collection rates, and the system "live" time was estimated near $99 \%$.

The data rate in the production runs was significantly higher (live time $\sim 75 \%$ ), initially causing issues with the data acquisition stability. The stability issue was rectified during the first phase of the experiment. A more serious issue is the loss of correlated data between the ADC and TDC data; one cannot associate the timing information from the TDC with the energy information from the ADC. Efforts were made to understand the ADC-TDC correlation issues, and a simple solution has not yet been determined. This issue is still under examination. In the data analysis, the TDC data is currently ignored.

\subsubsection{Gain calibrations}

The gains of the HPGe detectors drifted during the experiment. This drift had to be corrected on a runby-run basis. All eight leaves often had small gain change following a liquid nitrogen fill period. The HPGe detectors were filled every twelve hours, near 9 a.m. and 9 p.m.

The fourth leaf of the first clover had the most dramatic gain shifts, and a new calibration is needed for almost every run. For some runs, the detector element drifts out of calibration and should either be ignored for that run, or altered on an event-by-event basis.

The second leaf of this same detector also had gain drift issues during the second phase of the experiment. The variation of the gain over the experiment was about $1 \%$. To address this issue, the energy calibration of this leaf was completed on a run-by-run basis.

The fourth leaf of the first clover also had gain stability issues when the neutron field changed. Figure 12 shows the energy of the 1174- and $1332-\mathrm{keV}$ lines from ${ }^{60} \mathrm{Co}$ when the beam is turned off and on for runs $149-158$. 


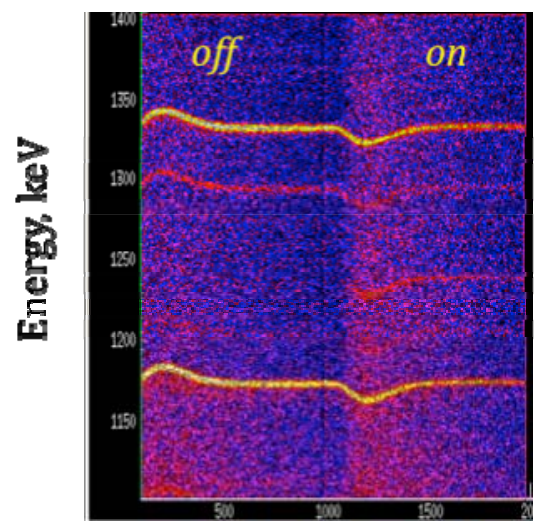

TAC value

Figure 12: HPGe energy for leaf 4 of clover 1 relative to the TAC value. The energy significantly shifts when the neutron beam turns off or on.

The effect from the neutrons shifts the gain calibration; for all photon energies the shift is equivalent. Figure 13a shows the energy change for the 186-, 511-, 1174- and 1332-keV gamma-rays. In addition, the shift when the beam is turned off or on is of the same magnitude, although in a different direction. Figure $13 \mathrm{~b}$ shows the magnitude of the shift for the average of the 1174- and 1332-keV transitions. A log-normal fit to the data approximates the experimental values well and can be used to correct the offset.

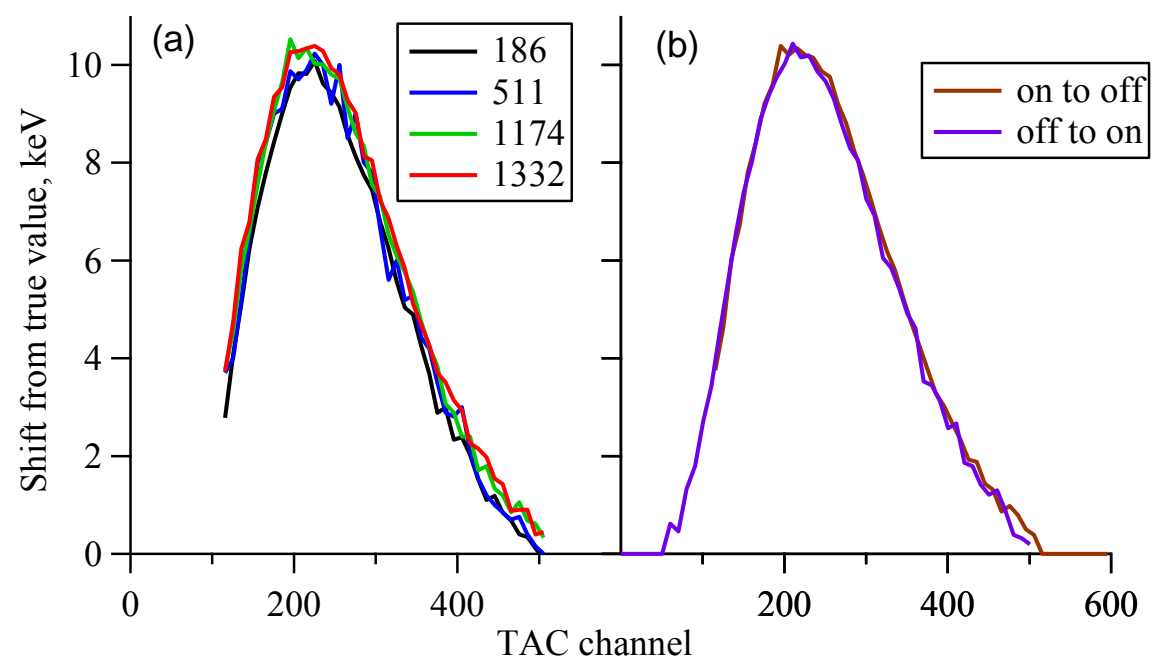

Figure 13: Energy shifts for neutron flux changes in leaf 4 of clover 1. All energies exhibit the same gain shift (a), and the magnitude of the shift is equal, though opposite in sign, when the neutron beam turns on/off (b). Note that the "off-to-on" data is opposite in sign and the TAC value is shifted by $50 \mu$ s to overlay the "on-to-off" shift.

Leaf 3 of clover 1 also exhibits an energy shift when the neutron flux changes, although the effect is much less than for leaf 4. A similar analysis and fit was performed for leaf 3 with good results. 


\subsubsection{Beam status}

An additional complication in the analysis is the instability of the beam status. The on/off timing has been observed to reverse for unknown reasons. The beam on/off status can be easily observed by a coincidence between the HPGe-beam TAC and the scintillators. Figure 14 highlights the beam changes for three runs during the second phase of the experiment.

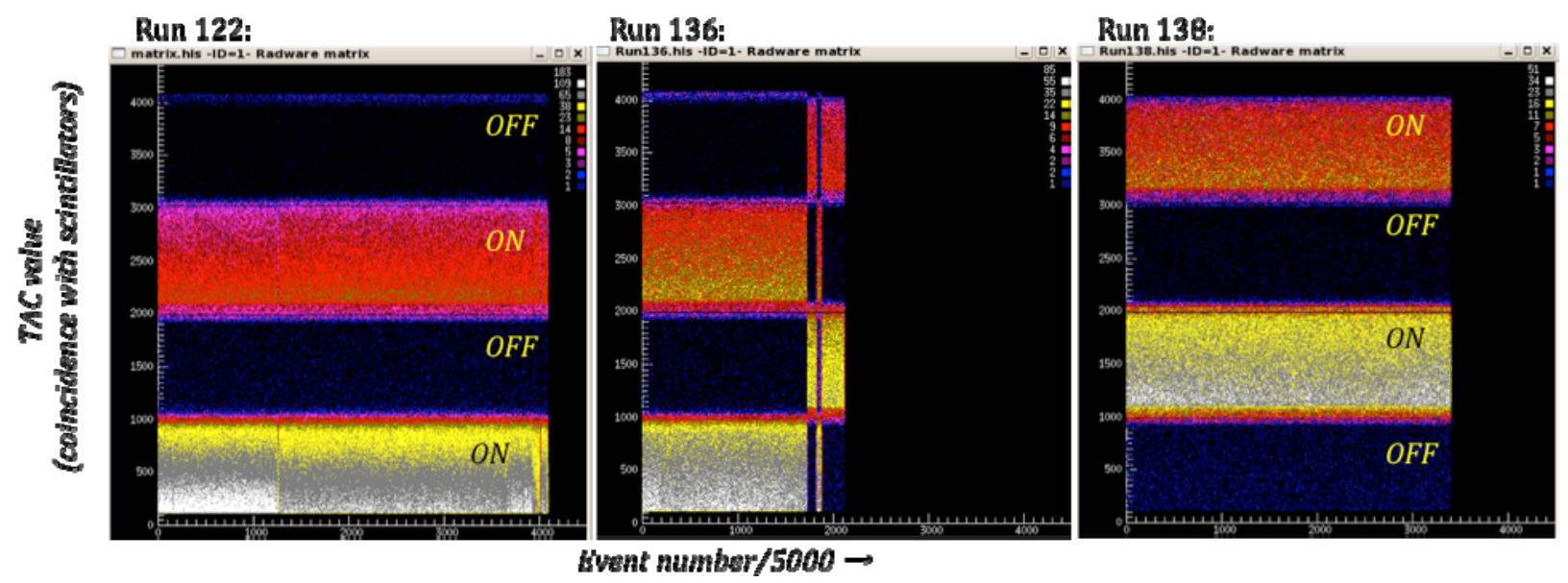

Figure 14: HPGe-beam TAC value in coincidence with the scintillators as a function of event number. The event number is roughly proportional to time. All three scintillators used counted in the same manner; i.e., this observation is not due to scintillator noise.

The beam status changes could not be correlated to any known events taking place at the experiment (e.g., run stopping, cave entry, HPGe filling). For most runs, careful selection of the beam on/off times can be made as a function of event number. Runs 148, 161, and 162 do not have retrievable data as the beam status was in a constant state of flux. Figure 15 shows the TAC-scintillator coincidence as a function of event number for run 161 .

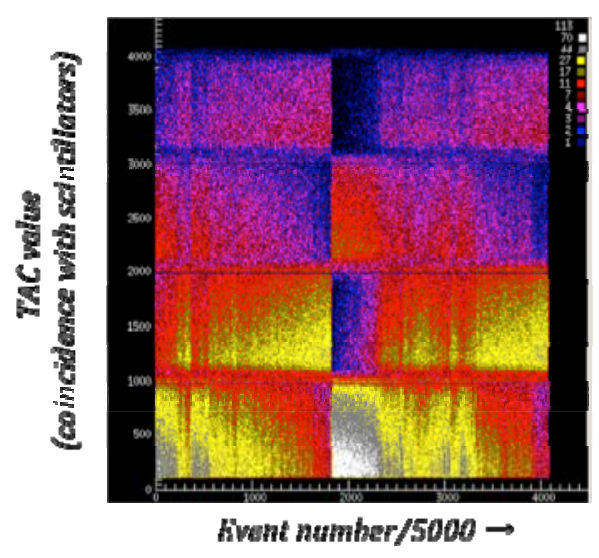

Figure 15: HPGe-TAC value in coincidence with the scintillators as a function of event number for run 161 
The beam status issue may be related to poor beam focusing and transmission of the primary deuterium beam. For the neutron production, very few diagnostics are available to the beam technicians to provide a quality tune. Instabilities and poor beam delivery were noted at times during the experiment.

\subsubsection{Spectra constituents}

An initial pass at the spectral components was made to ensure the experiment operated as expected. Runs 149 - 158 largely exhibited a stable beam status, and the neutron effects on leaf 3 and 4 of clover 1 could be corrected.

A gamma-energy vs. TAC time matrix was constructed, and gates placed on the beam off and beam on time periods. The large continuum backgrounds are subtracted off to accentuate the presence of peaks and allow the spectra to be compared more efficiently. An example of the continuum subtraction is shown in Figure 16.

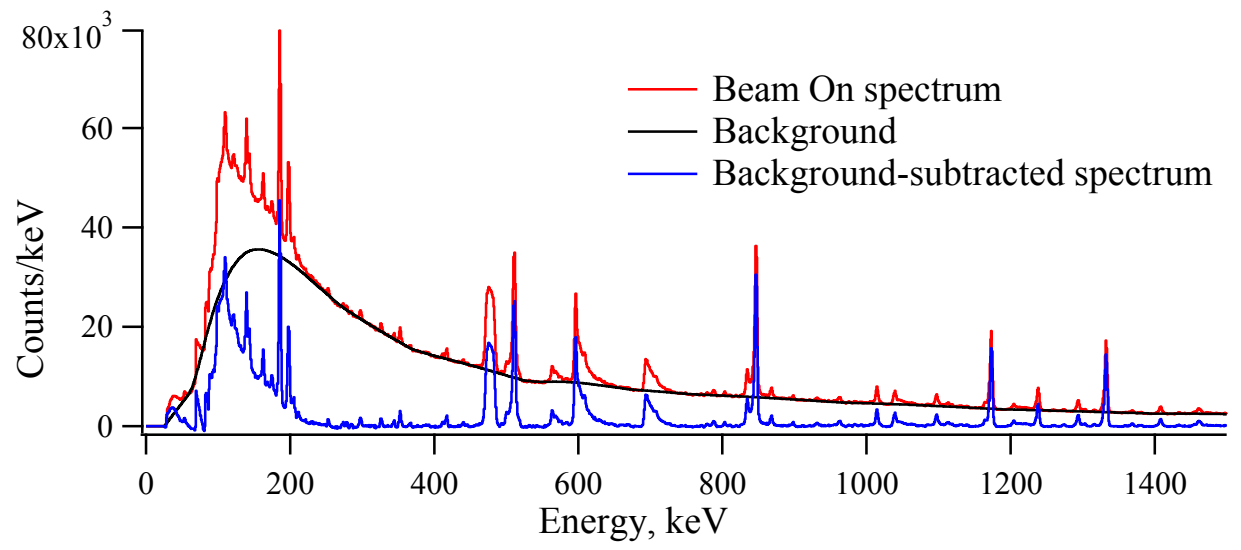

Figure 16: Sample of background subtraction using the gamma spectrum collected during the beam on period for runs $149-158$

A comparison of the beam off and on spectra are shown in Figure 17 and discussed below. 


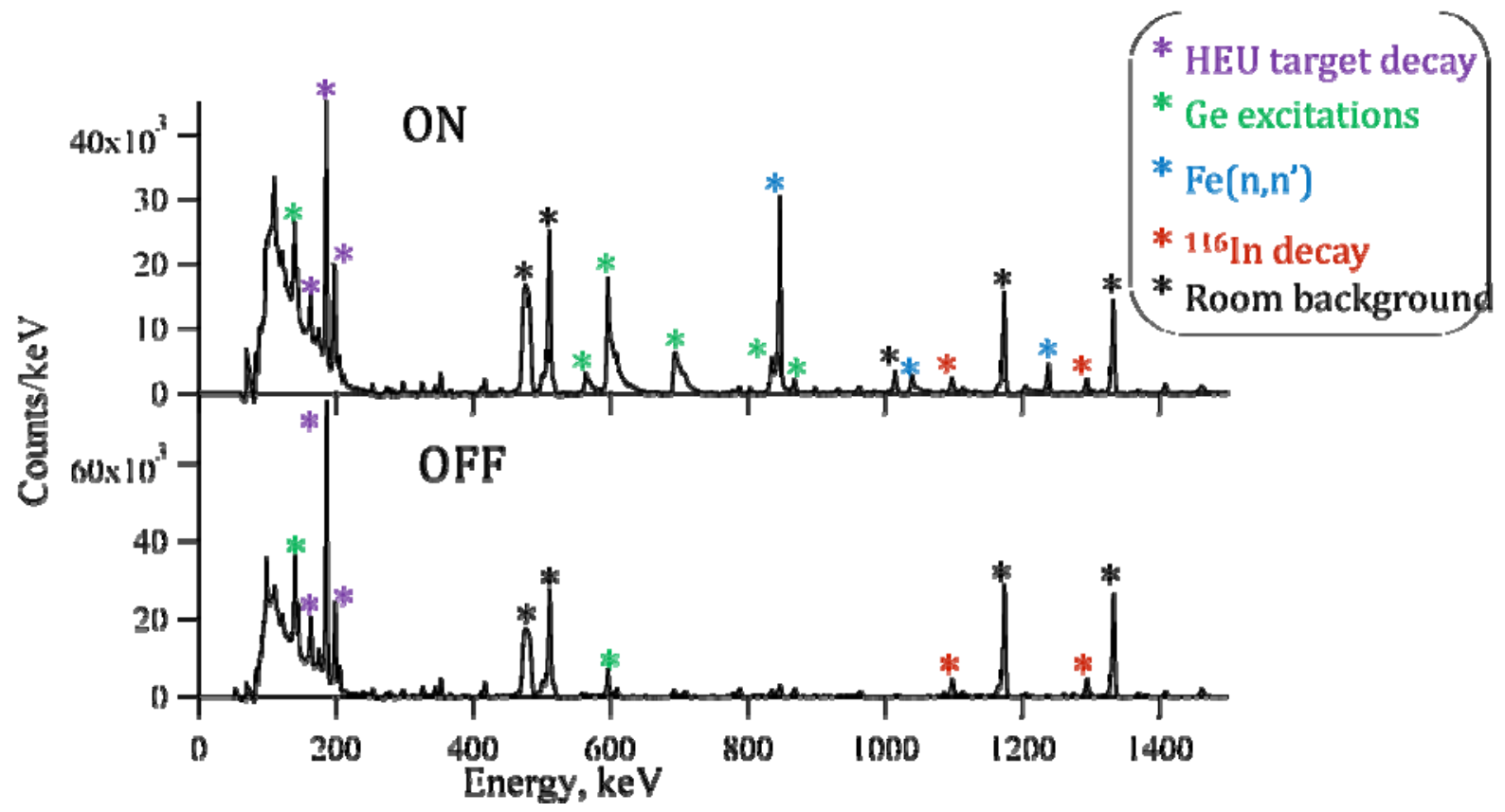

Figure 17. Gamma spectra gated by beam on and off conditions for runs $149-158$

\subsubsection{Radioactive decay of the HEU target (*)}

The dominant gamma-rays from the target decay are the 186-, 162-, and 205-keV transitions from the decay of ${ }^{235} \mathrm{U}$ to ${ }^{231} \mathrm{Th}$. The main radioactive decay path follows:

- ${ }^{235} \mathrm{U}\left(\alpha, \mathrm{T}_{1 / 2}=7 \times 10^{8} \mathrm{y}\right) \rightarrow{ }^{231} \mathrm{Th} ; \mathrm{E}_{\mathrm{\gamma}}=109,144,163,186,205 \mathrm{keV}$

- ${ }^{231} \mathrm{Th}\left(\beta^{-}, \mathrm{T}_{1 / 2}=25 \mathrm{~h}\right) \rightarrow{ }^{231} \mathrm{~Pa}$

- ${ }^{231} \mathrm{~Pa}\left(\alpha, \mathrm{T}_{1 / 2}=3 \times 10^{4} \mathrm{y}\right) \rightarrow{ }^{227} \mathrm{Ac} ; \mathrm{E}_{\gamma}=284,300,303,330 \mathrm{keV}$

- ${ }^{227} \mathrm{Ac}\left(\beta^{-}, \mathrm{T}_{1 / 2}=22 \mathrm{y}\right) \rightarrow{ }^{227} \mathrm{Th}$

- ${ }^{227} \mathrm{Th}\left(\alpha, \mathrm{T}_{1 / 2}=19 \mathrm{~d}\right) \rightarrow{ }^{223} \mathrm{Ra} ; \mathrm{E}_{\gamma}=211,236,256,286,290,300,305,330,334 \mathrm{keV}$

- ${ }^{223} \mathrm{Ra}\left(\alpha, \mathrm{T}_{1 / 2}=11 \mathrm{~d}\right) \rightarrow{ }^{219} \mathrm{Rn} ; \mathrm{E}_{\gamma}=144,154,269,324,338,445 \mathrm{keV}$

- ${ }^{219} \mathrm{Rn}\left(\alpha, \mathrm{T}_{1 / 2}=4 \mathrm{~s}\right) \rightarrow{ }^{215} \mathrm{Po} ; \mathrm{E}_{\gamma}=271,402 \mathrm{keV}$

- ${ }^{215} \mathrm{Po}\left(\alpha, \mathrm{T}_{1 / 2}=0.002 \mathrm{~s}\right) \rightarrow{ }^{211} \mathrm{~Pb}$

- ${ }^{211} \mathrm{~Pb}\left(\beta, \mathrm{T}_{1 / 2}=38 \mathrm{~m}\right) \rightarrow{ }^{211} \mathrm{Bi} ; \mathrm{E}_{\gamma}=405,427,832 \mathrm{keV}$

- ${ }^{211} \mathrm{Bi}\left(\alpha, \mathrm{T}_{1 / 2}=2 \mathrm{~m}\right) \rightarrow{ }^{207} \mathrm{Tl} ; \mathrm{E}_{\gamma}=351 \mathrm{keV}$

- ${ }^{207} \mathrm{Tl}\left(\beta^{-}, \mathrm{T}_{1 / 2}=5 \mathrm{~m}\right) \rightarrow{ }^{207} \mathrm{~Pb}$ (stable)

where gamma-ray energies are listed for decays with $>1 \%$ intensity.

\subsubsection{Iron excitations $(*)$}

Prompt de-excitations attributed to ${ }^{56} \mathrm{Fe}$ are easily observed in the beam-on spectrum. Iron-56 is the primary isotope in natural iron, with $91.75 \%$ abundance. Note that the iron excitations seen here are due 
not only to the iron foil of the HEU target; background runs with no target (runs 169 - 170) show similar results.

\subsubsection{Germanium excitations (*)}

Germanium excitations are seen in both the beam on and off spectra. The observed transitions are largely due to thermal neutron captures on the stable germanium isotopes of the gamma detector system. Germanium has high cross sections for neutron capture: ${ }^{70} \mathrm{Ge}(3.5 \mathrm{~b}),{ }^{72} \mathrm{Ge}(1.0 \mathrm{~b}),{ }^{73} \mathrm{Ge}(14 \mathrm{~b}),{ }^{74} \mathrm{Ge}(0.5$ b) and ${ }^{76} \mathrm{Ge}(0.4 \mathrm{~b})$ [Hasselgren 1972].

\subsubsection{Indium-115 decay (*)}

A sample of ${ }^{115}$ In was placed in the cyclotron vault near the thick neutron production target. This material was irradiated and counted as part of a separate activity and was not intended to interfere with the isomer work. However, gamma decays from the isomeric and beta decay of ${ }^{116}$ In $\left(\mathrm{T}_{1 / 2}=2.2\right.$ seconds, 14 seconds, and $54 \mathrm{~min}$; from neutron capture on ${ }^{115} \mathrm{In}$ ) were clearly observed as background lines.

\subsubsection{Room background (*)}

A significant ${ }^{60} \mathrm{Co}$ contamination that does not appear to be local is constantly present in the caves. A contamination with decay energies similar to ${ }^{152} \mathrm{Eu}$, whose origin is unknown, is also present. The ${ }^{60} \mathrm{Co}$ and ${ }^{152} \mathrm{Eu}$ contaminations were seen in the beam development runs as well. Neutron excitations on aluminum and other materials present in the cave reactions were also noted in the HPGe spectra.

\subsubsection{Higher resolution spectra}

The figures below provide higher resolution for peak identification. The beam-off spectra have more counts due to the higher live time of the data acquisition system. The color-coded legend is the same as above. 


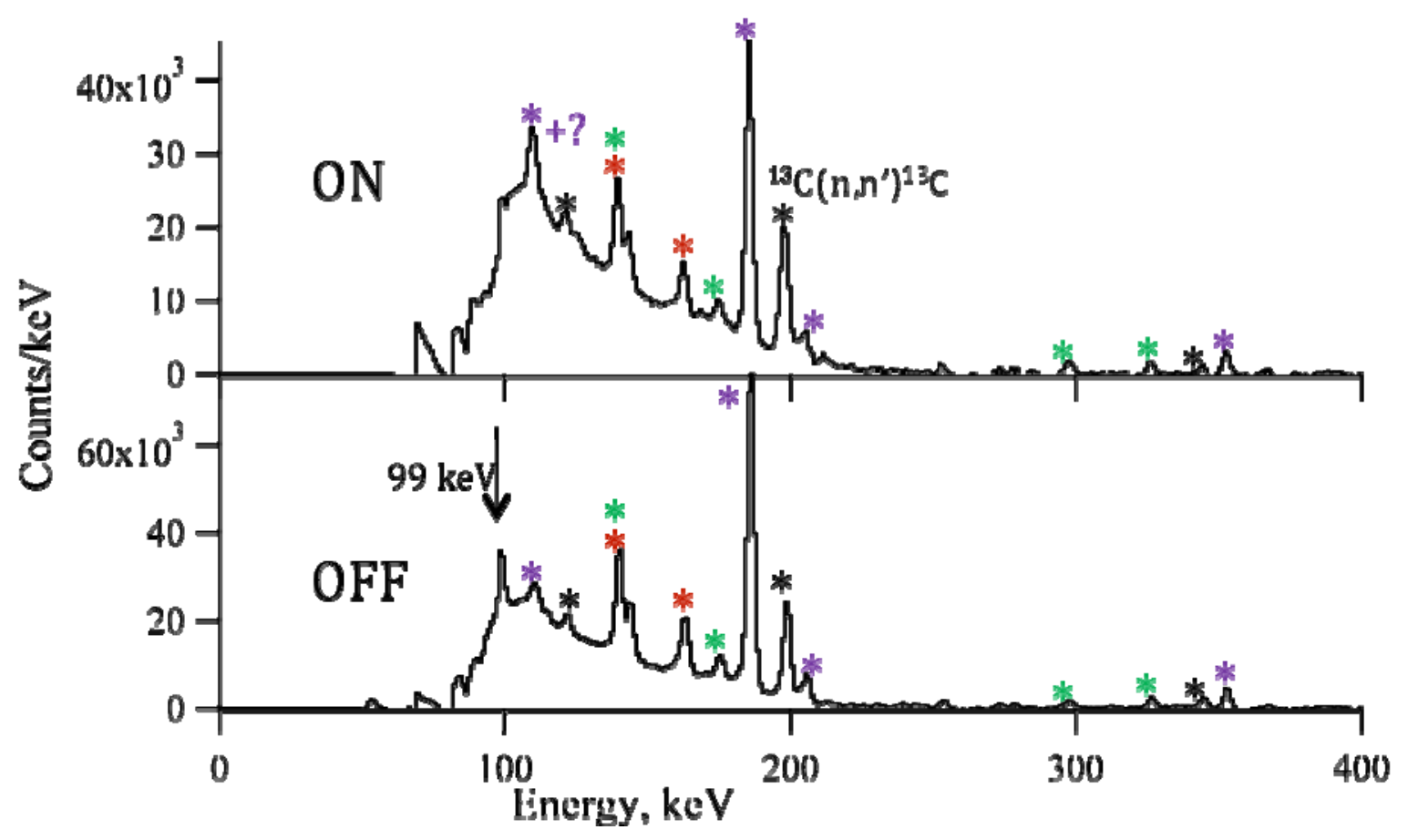

Figure 18: Beam on/off spectra from 0 to $400 \mathrm{keV}$

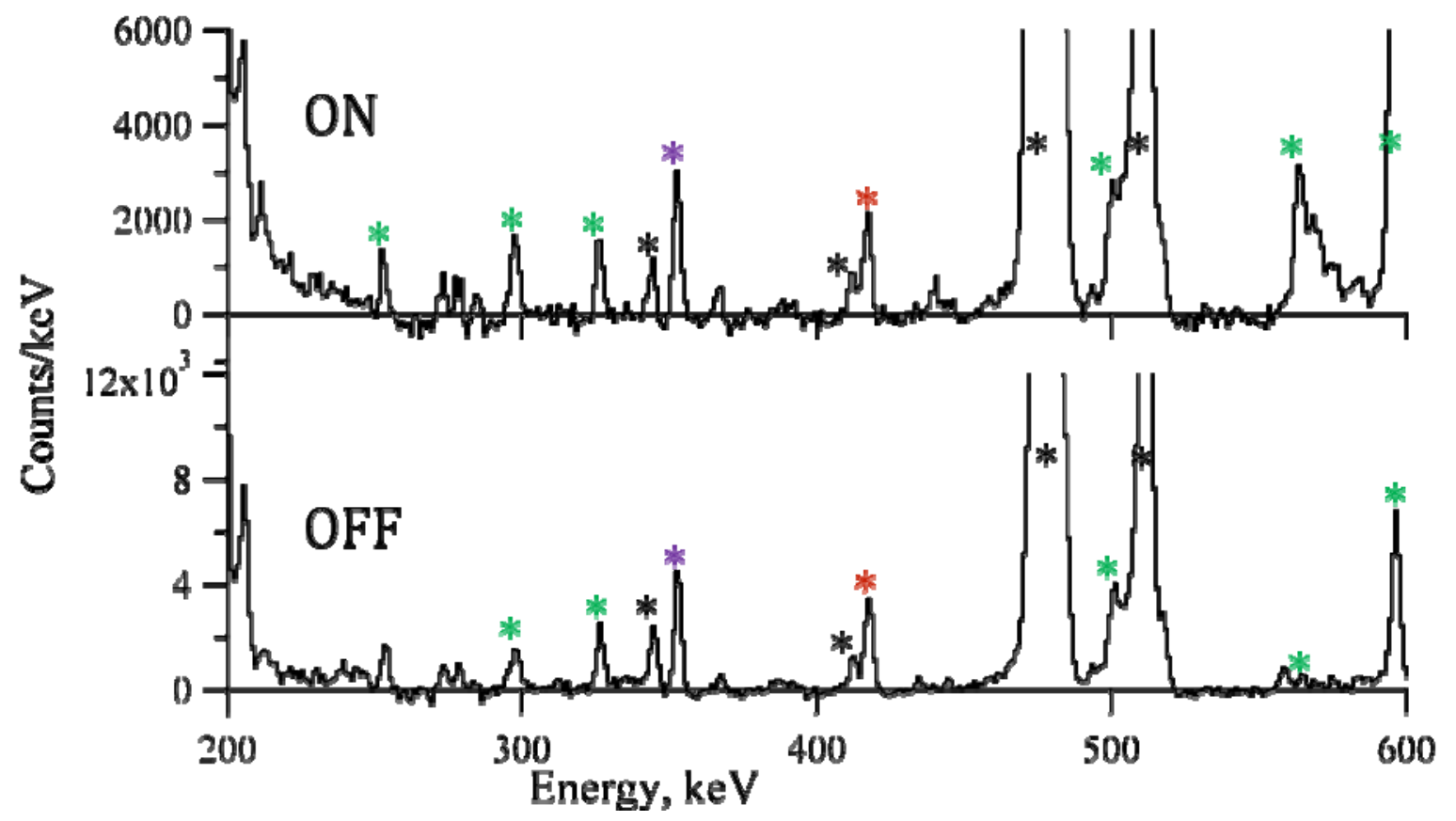

Figure 19: Beam on/off spectra from 200 to $600 \mathrm{keV}$ 


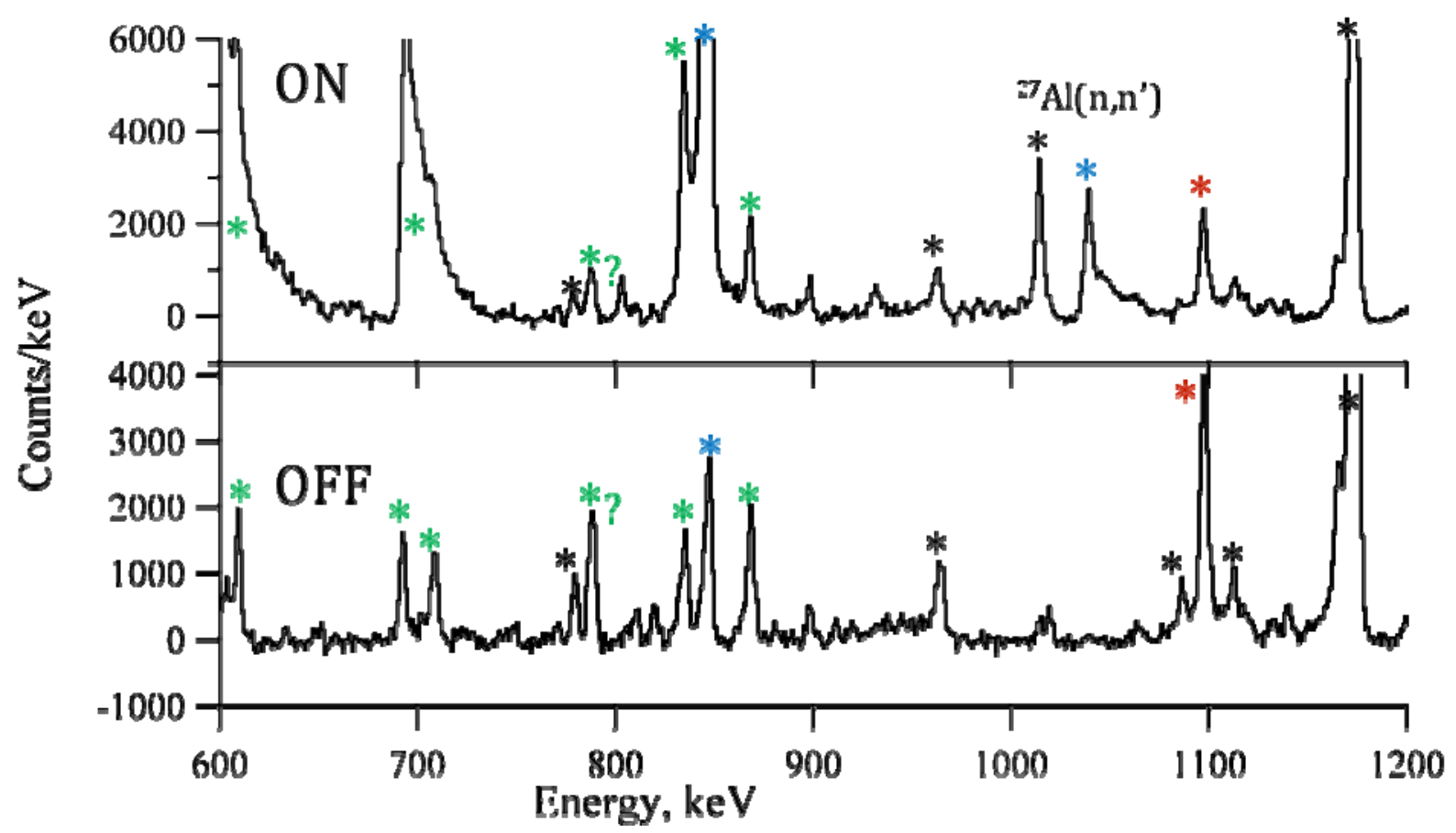

Figure 20: Beam on/off spectra from 600 to $1200 \mathrm{keV}$

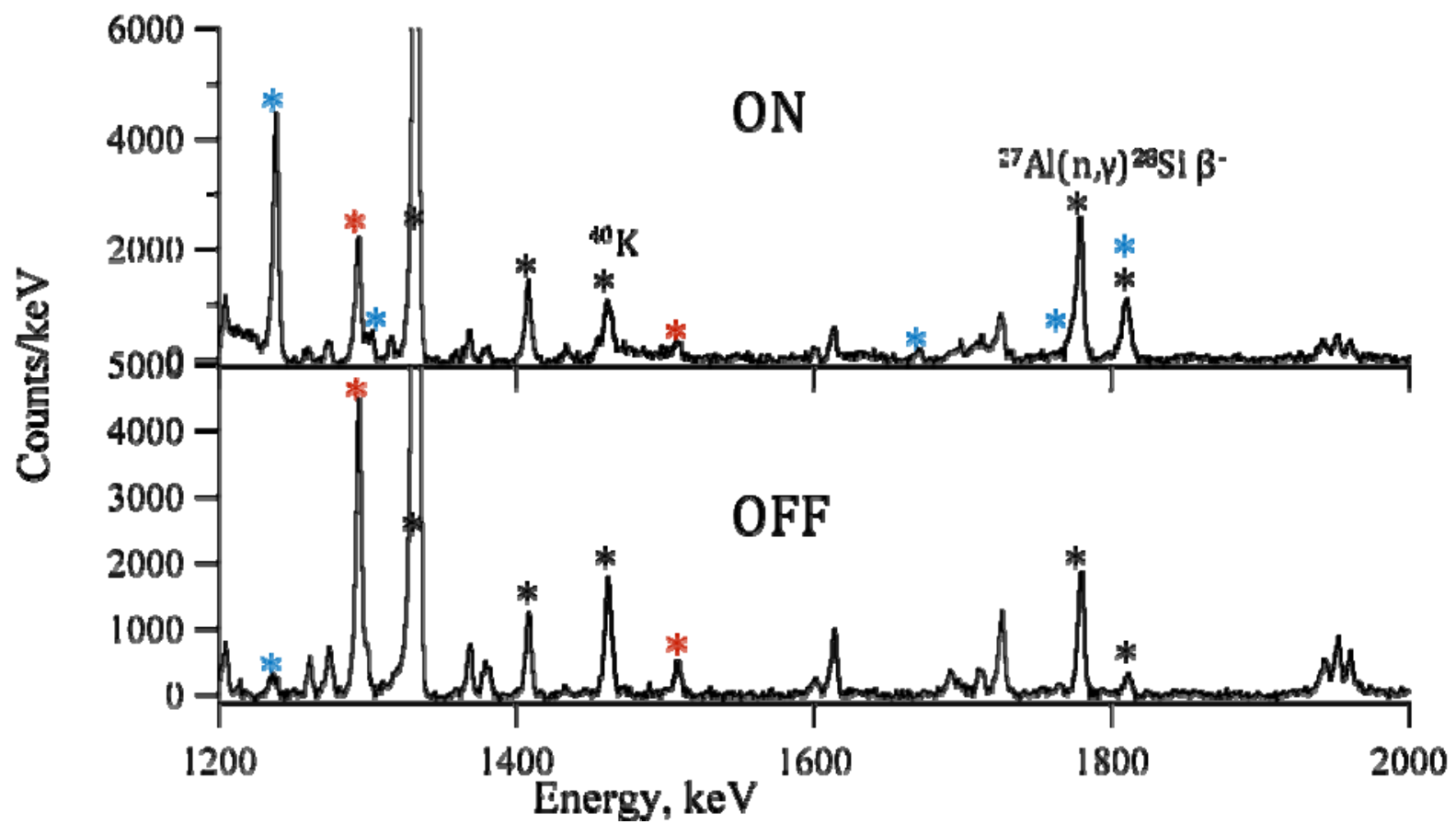

Figure 21: Beam on/off spectra from 1200 to $2000 \mathrm{keV}$ 


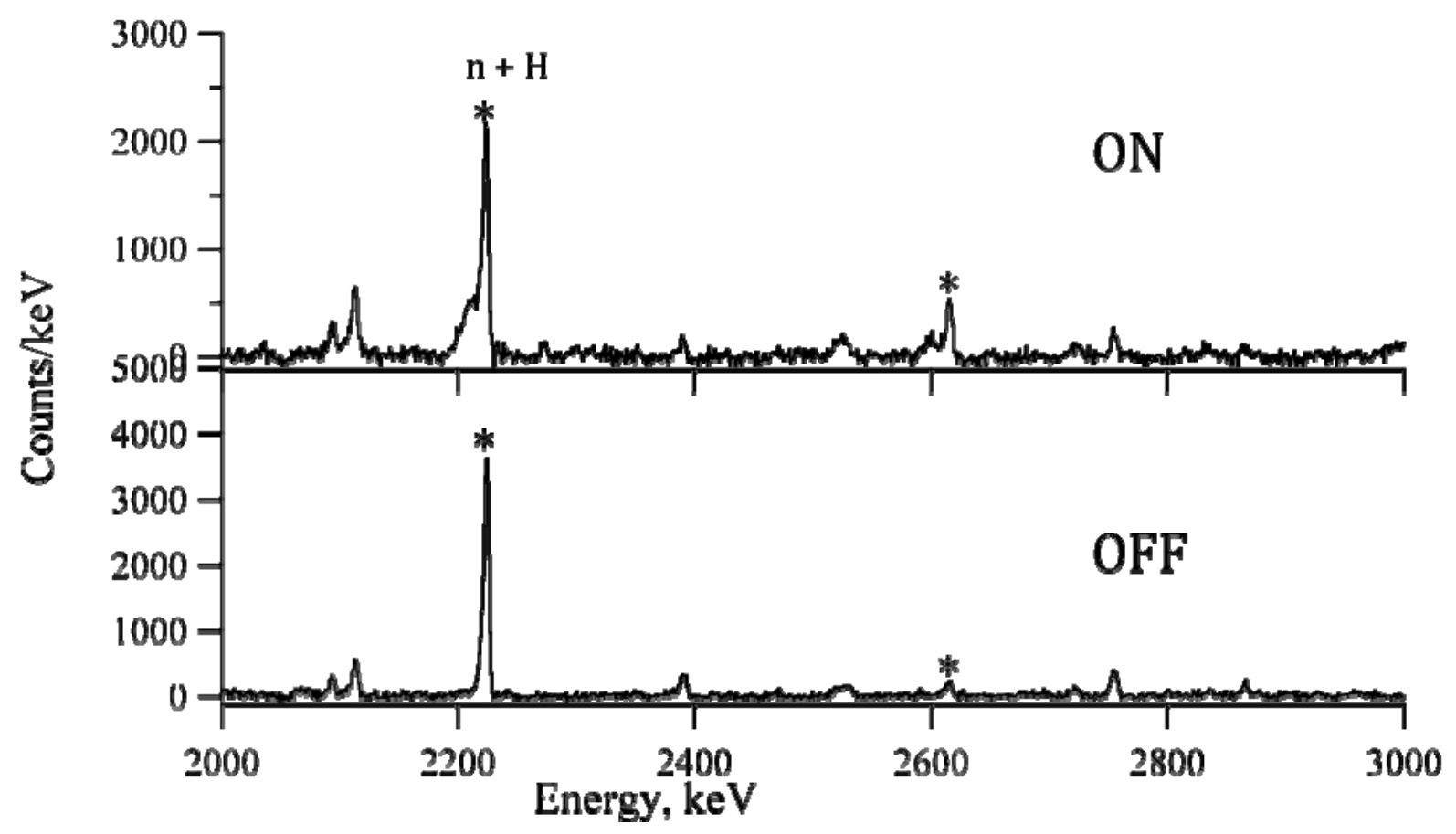

Figure 22: Beam on/off spectra from 2000 to $3000 \mathrm{keV}$

\subsection{Conclusion}

The project started FY2010 reviewing the beam test data acquired at TUNL in September 2009. Based on results from those measurements, the project management decided to conduct the measurements at the 88" cyclotron at LBNL, which provided similar neutron flux but better beam time structure for these measurements. PNNL, LLNL and LBNL conducted test measurements in March 2010 to study issues such as beam intensity, beam profile, and background rates for the measurements. Neutron production measurements were conducted in July 2010 at LBNL. The data from those measurements are still under analysis; however, there were some critical issues in the data acquisition system that limit the utility of the data. These issues include significantly less than $100 \%$ correlation between the recorded energy information and the recording timing information. A secondary timing scheme involving a time-toamplitude convertor was used during the measurements. It is possible that this secondary timing information may enable the successful analysis of the experimental data.

Future work will include a follow-up measurement scheduled for December 2010 at LBNL. Lessons learned from the July 2010 measurements will be incorporated into these new measurements. Analysis of both the July and December experiments will be completed in a few months. The project will draft a research paper for submission to a peer-reviewed journal if the conclusions from the measurements warrant publication. 


\subsection{References}

Chadwick, MB, et al. 2006. "ENDF/B-VII.0: Next Generation Evaluated Nuclear Data Library for Nuclear Science and Technology.” Nuclear Data Sheets 107(12): 2931-3060.

Chatterjee, A, et al. 1981. "Excitation of the U-238(M) Shape Isomer by Neutron Bombardment." Physical Review C 23(4):1629-34.

Hasselgren, A. 1972. "Deuteron Stripping and Thermal Neutron Capture $\gamma$-Reactions on the ${ }^{72,74,76} \mathrm{Ge}$ Isotopes." Nuclear Physics A 198(2):353-79.

Kantele, J, et al. 1984. "Reinvestigation of the Gamma-Branch from the U-238 Shape Isomer." Physical Review C 29(5):1693-98.

Meulders, JP, and et al. 1975. "Fast Neutron Yields and Spectra from Targets of Varying Atomic Number Bombarded with Deuterons from 16 to $50 \mathrm{MeV}$ (for Radiobiology and Radiotherapy)." Physics in Medicine and Biology 20(2):235.

Ressler, JJ, et al. 2010. "Fission Fragment Isomers Populated Via ${ }^{6} \mathrm{Li}+{ }^{232} \mathrm{Th} . "$ Physical Review C 81(1):014301.

Ressler, JJ, JA Caggiano, and GA Warren. 2009b. Annual Progress Report for Actinide Isomer Detection (2009). Report No. PNNL-18868, Pacific Northwest National Laboratory, Richland, WA.

Wolf, KL and JW Meadows. 1974. Bulletin of American Physical Society 19: 595. 


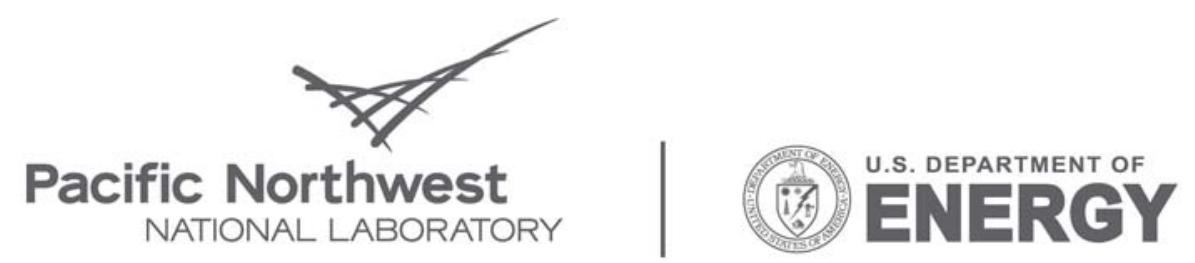

Proudly Operated by Battelle Since 1965

902 Battelle Boulevard

P.O. Box 999

Richland, WA 99352

1-888-375-PNNL (7665)

www.pnl.gov 